\title{
KOMUNIKASI TERAPEUTIK TENAGA KESEHATAN TERHADAP ORANG DENGAN GANGGUAN JIWA PASCA PASUNG(STUDI KASUS KOMUNIKASI TERAPEUTIK ODGJ PASCA PASUNG)
}

\author{
Sri Wahyuningsih ${ }^{1}$, Susanne Dida ${ }^{2}$, Jenny Ratna Suminar ${ }^{2}$, Yanti Setianti ${ }^{2}$ \\ ${ }^{1}$ Fakultas Ilmu Sosial dan Budaya, Universitas Trunojoyo Madura \\ ${ }^{2}$ Fakultas Ilmu Komunikasi, Universitas Padjadjaran \\ naningunijoyo@yahoo.co.id
}

\begin{abstract}
ABSTRAK
Tujuan penelitian adalah ingin mengetahui bagaimana komunikasiterapeutik tenaga kesehatan terhadappasien ODGJ pasca pasung di Posyandu Jiwa desa Wonorejo Kecamatan Singosari Kabupaten Malang provinsi Jawa Timur. Metode penelitiannya kualitatif berparadigma konstruktivis dengan pendekatan studi kasus, metode pengumpulan datanya adalah observasi, wawancara mendalam, dukumentasi, dan bahan audio visual. Teknik analisis datanya menciptakan dan mengorganisasikan file, membaca seluruh teks, membuat catatan pinggir, membentuk kode awal, mendiskripsikan kasus dan konteksnya, menggunakan agregasi kategorikal, menggunakan penafsiran langsung, menyajikan gambaran mendalam kasus menggunakan narasi, dan gambar. Validitas datanya triangulasi dan member check. Hasil penelitian komunikasi terapeutik ODGJ pasca pasung di Posyandu Jiwa desa Wonorejo yang dilakukan oleh tenaga kesehatan melalui pendekatan komunikasi terapeutik psikiater yang dibantu perawat adalah telepsychiatry dan terapi obat. Komunikasi terapeutik perawat yang dibantu kader jiwa adalah handycraft yaitu pembuatan kemoceng, sandal, bros, dan keset; Terapi psikoreligius dengan berdzikir, bersholawat, mengaji, dan tuntutan sholat; dan Terapi Aktivitas Kelompok adalah mengajak pasien bermain, bersosialisasi. Relevansi dengan teori Interaksi Simbolik, konsep pikiran bahwa bahasa dan interaksi adalah suatu sistem yang dapat memberikan simbol-simbol bermakna diantara hubungan psikiater, perawat, dan pasien, konsep diri bahwa setiap diri yang diperankan oleh tenaga kesehatan dan pasien ODGJ mempunyai nilai dari pandangan orang lain. Konsep masyarakat, pada particular other, bahwa tenaga kesehatan dan keluarga adalah orang yang paling dekat keberadaannya terhadap pasien ODGJ, sedangkan generalized other bahwa masyarakat wilayah dalam memandang ODGJ dekat dengan mereka, masyarakat wilayah luar mendiskriminasikan mereka.
\end{abstract}

Kata kunci: Komunikasi terapeutik, telepsychiatry, odgj pascapasung, teori interaksi simbolik

\section{THERAPEUTIC COMMUNICATION OF HEALTH WORKER FOR PEOPLE WITH MENTAL DISORDERS POST PASUNG}

\begin{abstract}
The purpose of the study was to find out how therapeutic communication of health personnel on postpasung ODGJ patients at the Posyandu Jiwa village in Wonorejo, Singosari Subdistrict, Malang Regency as a DSSJ guided by Dr. Radjiman Wediodiningrat Mental Hospital Lawang District, Malang District, East Java Province. The qualitative research method is constructivist paradigm with a case study approach, the data collection methods are observation, in-depth interviews, documentation, and audio-visual material. The data analysis technique creates and organizes files, reads the entire text, makes marginal notes, forms the initial code, describes the case and its context, uses categorical aggregation, uses direct interpretation, presents an in-depth picture of cases using narration, and images. The validity of the data is triangulation and member check. The results of the post-pasung ODGJ therapeutic communication study at the Posyandu Jiwa village in Wonorejo were carried out by health workers through a psikiater communication therapeutic approach with nurse, the treatment of telepsychiatry and drug therapy. A nurse communication therapeutic approach, the treatments are handicrafts, namely making duster, sandals, brooches, and mats; Psychological treatment with dhikr, praying, reciting, and praying demands; and Therapy Group Activity is to invite patients to play, socialize. Relevance to the Symbolic Interaction theory, the concept of mind that
\end{abstract}


language and interaction is a system that can provide meaningful symbols between the relationship of psychiatrists, nurses, and patients, self-concept that each person played by health workers and ODGJ patients has value from the viewpoint of others. The concept of society, in a particular other, is that health workers and families are the closest people to ODGJ patients, whereas other generalized people in the area view ODGJ as close to them, outside communities discriminate against them.

Keywords: Therapeutic communication, telepsychiatry, odgj post pasung, symbolic interaction theory

\section{PENDAHULUAN}

Tim psikiatrik dari Rumah Sakit Jiwa Dr Radjiman Wediodiningrat Lawang instalasi PKRS, perawat, kader jiwa dan pemerintah desa mengidentifikasi desa Wonorejo Kecamatan Singosari Kabupaten Malang, hasilnya adalah banyak kasus kejiwaan diantaranya ODGJ (Orang Dengan Gangguan Jiwa) yang berjumlah 37 orang dan yang dipasung berjumlah 8 orang dalam satu desa. Hal itu segera diatasi oleh tenaga kesehatan untuk dievakuasi dalam perawatan Rumah Sakit Jiwa Dr Radjiman Wediodiningrat Lawang Kabupaten Malang.

Menurut keluarga ODGJ yang ada di desa Wonorejo untuk mencari jalan yang terbaik dalam penyelesaian penderitaan anggota keluarganya dengan pergi ke dukun. Sebelum mendapatkan perawatan di Rumah Sakit Jiwa, mereka bersama keluarganya mengandalkan pengobatan secara traditional healing yaitu pergi ke dukun atau ke kyai dengan maksud akan tertangani penyakitnya, tetapi justru sebaliknya penyakit gangguan jiwa itu tidak tertangani tetapi semakin parah. Budaya pergi kedukun sering dilakukan oleh para keluarga yang mempunyai anggota keluarganya ODGJ. Mereka sangat percaya bahwa pengobatan dari dukun atau kyai akan menyembuhkan sakit gangguan jiwa anggota keluarganya.

Seperti penuturan bapak Wagiran orang tua salah satu dari ODGJ pasca pasung berinisial "W":

"kulo sering bawa anak kulo ke dukun, sameniko kulo teng dukung niku bayar nganti 100 sampai dengan $150 \mathrm{rb}$, ngendikan dukun kulo dipun mendem sego liwet teng halaman omah, sak meniko ku mimpi wonten ayam alas kabur eh anak kulo kumat malih"..(Saya sering bawa anak saya ke dukun, sekali datang sampai menghabiskan uang 100 ribu sampai dengan 150 ribu, kata dukun itu saya di suruh mendem sego liwet di halaman rumah, nah setelah itu saya mimpi ada ayam alas kabur lho setelah itu kumat lagi anak saya) (Hasil wawancara salah satu orang tua ODGJ pascapasung Bapak Wagiran, 22 Oktober 2019 di desa Wonorejo Kecamatan Singosari Kabupaten Malang).

Salah satu penuturan orang tua ODGJpasca pasung di desa Wonorejo, keluarga yang lainnya pun bertindak demikian, sebelum adanya pengobatan di Posyandu Jiwa. Keluarga pasien ODGJ post pasung seringkali membawa anaknya yang mengidap ODGJ ke dukun dengan harapan sembuh dengan metode dukun yang dipakai atau traditional healing tetapi pada kenyataannya adalah mengalami "kumat" atau kekambuhan.

Apa yang disampaikan oleh Bapak "W" diperkuat oleh salah satu perawat Puskesmas Ardimulyo Kecamatan Singosari Ibu "T":

"Rata-rata pasien sudah pernah "disuwuk" dibawa ke orang pinter selalu memakai menyan (dupo ratus)" (Hasil wawancara dengan Ibu Tyas Perawat Puskesmas Ardimulyo pada tanggal 20 Agustus 2018 di desa Wonorejo Kecamatan Singosari Kabupaten Malang).

Desa Wonorejo adalah salah satu cakupan wilayah kerjanya Puskesmas Ardimulyo, selain desa-desa lain yang berada di kecamatan Singosari. Tetapi desa Wonorejo adalah merupakan desa yang perlu mendapatkan perhatian lebih dari berbagai elemen masyarakat karena kasus kejiwaan dengan ODGJ yang berjumlah 37 orang dengan ODGJ pasung 8 orang.

Keluarga memasung mereka karena merasa kesal dan capek dengan kondisi ODGJ yang selalu membuat ulah di keluarganya sendiri maupun membuat ulah terhadap lingkungan masyarakat, dengan bertindak kekerasan melakukan pengrusakan kebun orang lain, memukul, menyerang atau "membacok" 
dengan benda tajam kepada orang lain maupun keluarganya sendiri. Sehingga keluarganya merasa malu dengan mempunyai anggota keluarga ODGJ sehingga dipasung agar tidak berulah kembali ke lingkungan masyarakat maupun keluarganya sendiri.

Hasil Observasi dan Wawancara peneliti dari bulan April sampai dengan November 2018, faktor pemicu banyaknya ODGJ di desa Wonorejo adalah hubungan interpersonal, kehilangan anggota keluarganya, perceraian, kemiskinan, keturunan (genitas), penyakit fisik, dan pekerjaan. Hal itu menjadi penyebab beberapa orang di desa Wonorejo menderita gangguan jiwa, karena terlalu berpikir berlebihan, akhirnya ada sistem dalam otak yang tidak kuat untuk bekerjasama sehingga menyebabkan kejiwaannya terganggu.

Melihat realitas tersebut, lahirlah hasil MMD (Musyawarah Masayarakat Desa) yang bertempat di desa Wonorejo, yaitu komitmen bersama antara Puskesmas Ardimulyo, desa Wonorejo, pihak kecamatan Singosari, Rumah Sakit Jiwa Dr Radjiman Wediodiningrat Lawang (RSJRW), Dinas Sosial Kabupaten Malang, membentuk posyandu jiwa dan Desa Siaga Sehat Jiwa (DSSJ) untuk menangani masalah jiwa di wilayah tersebut, menghilangkan budaya pengobatan ke dukun dan mencegah terjadi pemasungan lagi (re pasung). Musyawarah Masyarakat Desa yang dilakukan pada akhir tahun 2016 menghasilkan kesepakatan untuk membentuk Posyandu Jiwa, demikian penyampaian Kepala Instalansi Promosi Kesehatan Rumah Sakit Jiwa Malang adalah sebagai berikut:

"Pada saat itu komitmen/kesepakatan MMD (Musyawarah Masyarakat Desa) ini dilakukan pada akhir tahun 2016, kemudian terbentuklah posyandu jiwa pada bulan Mei tahun 2017 diresmikan oleh Bupati Malang Rendra Krisna" (hasil wawancara awal dengan Kepala Instalansi PKRS RSJRW Ibu Febry pada tanggal 1 Oktober 2018).

Posyandu Jiwa merupakan tempat dimana berkumpulnya aktivitas pemeriksaan kesehatan jiwa yang dilengkapi dengan berbagai terapi yang dilakukan oleh tenaga kesehatan kepada pasien ODGJ yang ada di desa Wonorejo Kecamatan Singosari Kabupaten Malang.
Posyandu Jiwa ini selalu ada aktivitas komunikasi antara tenaga kesehatan, kader jiwa dengan pasien-pasien ODGJ, dilengkapi dengan memanfaatkan perkembangan teknologi komunikasi dengan menggunakan metode telepsychiatry yaitu pemeriksaan kesehatan jiwa dengan berkonsultasi jarak jauh melalui media komputer dengan Skype, video call, chatting, email, yang terhubung dengan jaringan internet, konsultasi ini dilakukan antara psikiater dengan pasien ODGJ, perawat yang mendampingi ODGJ dengan psikiater guna mengetahui kondisi perkembangan pasien ODGJ setelah pemeriksaan sebelumnya di Rumah Sakit Jiwa Dr Radjiman Wediodiningrat Lawang. Telepsychiatry ini merupakan bagian dari komunikasi terapeutik, karena di dalamnya ada kegiatan observasi dan komunikasi antara psikiater, perawat ,dan pasien ODGJ.

Telepsychiatry dipelopori oleh PKRS (Promosi Kesehatan Rumah Sakit Jiwa) sebagai pilot project inovasi dari Rumah Sakit Jiwa Dr Radjiman Wediodiningrat (RSJRW). Hal ini sudah berjalan sejak tahun 2017 bulan Mei sampai saat ini menjadi rutinitas bulanan dalam pemerikasaan kesehatan jiwa ODGJ di desa Wonorejo. Telespychitry ini bagian dari komunikasi terapeutik antara psikiater, perawat dengan pasien ODGJ yang ada di desa Wonorejo dan pasien yang relaps atau kambuh artinya keluar masuk Rumah Sakit Jiwa Lawang berulang kali. Adanya telepsychiatry ini juga dilatar belakangi oleh laporan beberapa keluarga pasien yang kurang mampu secara finansial untuk berobat, sewa transportasi untuk pasien. Telepsychiatry ini dilakukan sebulan sekali dalam minggu ke-3 setiap hari Senin di desa Wonorejo Kecamatan Singosari Kabupaten Malang.

Langkah bersama yang diambil Rumah Sakit Jiwa Malang, Puskesmas Ardimulyo desa Wonorejo, pihak kecamatan Singosari, pihak Dinas Sosial setempat, dan Pemdes Wonorejo, dalam penyembuhan dan pemulihan ODGJ yang post pasung, adalah langkah yang tepat sesuai dengan Undang-Undang No. 23 Tahun 1992 tentang Kesehatan yaitu Upaya Kesehatan bagian pertama umum pasal 10 yaitu untuk mewujudkan derajat kesehatan yang optimal bagi masyarakat, diselenggarakan upaya kesehatan dengan 
pendekatan pemeliharaan, peningkatan kesehatan (promotif), pencegahan penyakit (preventif), penyembuhan penyakit (kuratif), dan pemulihan kesehatan (rchabilitatif) yang dilaksanakan secara menycluruh, terpadu, dan berkesinambungan. Melihat juga bahwa pada Tahun 2010 Indonesia memiliki program gerakan Indonesia bebas pasung didukung dengan Peraturan Menteri Kesehatan RI No. 54 tahun 2017 tentang penanggulangan pemasungan pada Orang Dengan Gangguan Jiwa (ODGJ). Pelaksanaan program bebas pasung pemerintah pusat, ditindaklanjuti pemerintah pusat Jawa Timur yaitu Tahun 2019 bebas pasung.

Langkah bersama yang dilakukan, bukanlah hal yang mudah karena banyak hambatan dan tantangan yang dialami oleh pihak RSJRW Lawang bersama tim beserta pemerintah desa Wonorejo dalam melakukan gerakan bebas pasung dan pengobatan atau pemulihan ODGJ yang ada di desa Wonorejo sehingga ODGJ yang statusnya pasung menjadi post pasung. ODGJ yang awalnya mengamuk-ngamuk, berperilaku berlebihan seperti melakukan gerakan yang berulang, berbicara sendiri, menyendiri, tidak bisa melakukan aktivitas sehari-hari, saat ini sudah berubah terkendali sejak adanya Posyandu Jiwa di desa Wonorejo.

Tim RSJRW Lawang bersama perawat puskesmas Ardimulyo beserta para kader yang ada di desa Wonorejo ketika, mereka membujuk kepada keluarga ODGJ untuk ditangani dengan membawanya ke Rumah Sakit Jiwa Lawang. ODGJ akan diberikan penanganan secara intensif selama kurang lebih 43 hari dalam standart masa pengobatan BPJS Rumah Sakit Jiwa Lawang.

Proses pengobatan selama di Rumah Sakit Jiwa Lawang mereka terlebih dahulu akan dimasukkan ke UGD untuk diperiksa, selanjutnya pasien ODGJ akan ditempatkan di Ruang gaduh gelisah untuk dilakukan tindakan pengobatan, dan terapi kurang lebih satu minggu, perlakuan komunikasi terapeutik belum intensif karena pasien ODGJ masih gaduh gelisah, selanjutnya setelah lebih tenang pasien ODGJ akan dipindahkan ke ruang intermediate yaitu ruang yang menampung sekelompok ODGJ yang lebih tenang dengan tujuan mereka bisa berinteraksi dan berkomunikasi dengan yang lain. Kemudian pasien ODGJ dengan kondisi yang lebih tenang untuk penanganan intensif secara berkelanjutan yaitu pengobatan, berbagai terapi, yang dilakukan psikiater dan perawat jiwa, kurang lebih satu bulan, di ruang Tenang ini pasien ODGJ lebih intensif mendapatkan perlakuan komunikasi terapeutik sehari sampai 3 kali dari perawat maupun psikiater. Setelah pasien ODGJ mampu melakukan aktivitas sehari-hari diantaranya makan, minum, mandi, berbicara dengan yang lain, psikiater menyatakan pulih dan sembuh dari gangguan jiwanya. Dilanjutkan kontrol bulanan ke RSJRW Lawang untuk melihat perkembangan kesehatan mental ODGJ yaitu dengan diperiksa dan diberi obat antipsychotics oleh psikiater tujuannya adalah mencegah kekambuhan dan gangguan jiwa yang berkepanjangan. (Hasil observasi dan hasil wawancara dengan psikiater dan perawat Posyandu Jiwa desa Wonorejo Kecamatan Singosari Kabupaten Lawang tahun 17 April 2018).

Adanya Posyandu Jiwa di desa Wonorejo Kecamatan Singosari Kabupaten Malang dengan dilengkapi metode telepsychiatry, TAK(Terapi Aktivitas Kelompok), Rehabilitasi Mental, sangat membantu mempermudah akses pasien-pasien ODGJ untuk kontrol kesehatan jiwanya lebih dekat, dan tidak harus pergi ke Rumah Sakit Jiwa Lawang lagi. Ada juga beberapa pasien ODGJ yang ada di desa Wonorejo hanya berobatnya ke puskesmas, mulanya karena gangguan jiwanya tidak tergolongkan akut. Tetapi dengan adanya kontrol kesehatan setiap bulannya di Posyandu Jiwa desa Wonorejo kekambuhan pasien ODGJ terminimalisir.

Penanganan pasien ODGJ di desa Wonorejo Kecamatan Singosari Kabupaten Malang Provinsi Jawa Timur, sangat memperhatikan budaya kesehatan, system dasar yang terdapat di budaya kesehatan menurut Mullavey, 1994; Sullivan, 2001 yang dikutip oleh (Mulyana, 2016: 86), bahwa terdapat tiga system dasar dalam budaya kesehatan yaitu Biomedical System (biomedis), Personalistic System (personalitik), dan Naturalistic System (pengobatan secara alami). Aplikasi pada sistem di atas sering kali ditekankan dalam pengobatan system biomedis dan sistem 
personalistik. Sistem Biomedis bahwa kesehatan dan penyakit adalah fenomena objektif yang disebabkan oleh factor tertentu yang dapat diuji secara ilmiah melalui laboratorium, Sedangkan sistem personalistik bisa disembuhkan melalui terapi-terapi spiritual dan psikoreligius. Dengan kata lain, sistem ini mengklaim bahwa tidak ada pengobatan secara supranatural, sambil mempertimbangkan bahwa faktor psikologis, sosial dan budaya bersifat sekunder atau tidak signifikan. Jadipenanganan yang dilakukan oleh tenagakesehatan pada pasien ODGJ di Posyandu Jiwa yang merupakan binaan Rumah Sakit Jiwa Lawang, adalah menggunakan dua pendekatan diantaranya adalah 1)System Biomedis dengan pemberian obat yang diminum secara langsung atau melalui injeksi sehari 2 kali, cek laboratorium dan perlakuan ECT (Electronic Convulsion Therapy) sebelumnya ketika berada di Rumah Sakit Jiwa Lawang di posyandu jiwa dilanjutkan pemeriksaan setiap bulannya dan pemberian obat sesuai kondisi masing-masing pasien ODGJ, dan 2)Sistem Personalistic, berbagai terapi termasuk komunikasi terapeutik, dan rehabilitasi mental diantaranya adalah terapi spiritual atau psikoreligius.

Di Posyandu Jiwa desa Wonorejo binaan RumahSakit Jiwa Lawang dalam penanganan pasien ODGJ, disamping menggunakan obatobatan, dalam pemulihan jiwanya tenaga kesehatan menggunakan teknik atau metode komunikasi terapeutik oleh perawat jiwa, psikiater, kader jiwa bersama keluarga turut terlibat dalam hal ini ketika pasien ODGJ posisi di rumah. Keterlibatan keluarga adalah hal yang penting dalam penyembuhan pasien ODGJ. Menurut Dr.Suryani, penyakit

Gangguan jiwa merupakan sebuah journey of challenge, perjalanan yang penuh tantangan. Mereka sulit untuk langsung sembuh. Membutuhkan proses yang panjang dalam penyembuhannya. Karena itu, membutuhkan pendampingan yang terus-menerus sampai pasien benar-benar kuat. Ketika sudah di rumah, dukungan dari keluarga dan lingkungan sekitarpun sangat dibutuhkan agar pasien dapat menjalani proses recovery atau penyembuhannya (Hendriyana, 2013).
Penelitian ini lebih menonjolkan keunikan yang spesifik, karena metode penelitian yang dipakai dalam penelitian ini adalah studi kasus.

Dari pra Riset hingga masa penelitian, peneliti banyak menemukan keunikan-keunikan dalam penanganan pasien-pasien ODGJ di Posyandu Jiwa desa Wonorejo Kabupaten Malang Provinsi Jawa Timur. Dari paparan latar belakang penelitian di paragraf-paragraf sebelumnya akan menggiring pokok permasalahan yang ada dalam penelitian beserta tujuan, manfaat, hasil dan model yang akan ditemukan dari hasil penelitian ini.

Berdasarkan paparan dalam latarbelakang penelitian, maka tujuan penelitian adalah Bagaimana komunikasi terapeutik tenaga kesehatan terhadap pasien ODGJpost pasung di Posyandu Jiwa desa Wonorejo Kecamatan Singosari Kabupaten Malang sebagai Desa Siaga Sehat Jiwa (DSSJ) Binaan Rumah Sakit Jiwa Dr RadjimanWediodiningratKecamatan LawangKabupaten Malang PropinsiJawa Timur.

\section{METODE}

Paradigma konstrukstivistik, suatu faham yang menyatakan bahwa positivisme dan post positivism merupakan paham yang keliru dalam mengungkapkan realitas dunia. Secara ontology, paradigm ini menyatakan bahwa realitas bersifat social sehingga akan menumbuhkan teori atas realitas majemuk.

Penelitian ini menggunakan metode kualitatif dengan pendekatan studi kasus. Studi kasus mencakup studi tentang suatu kasus dalam kehidupan nyata, dalam kontek satau setting kontemporer (Yin, 2009) dikutip oleh Cresswell, 1998:62). Penelitian studi kasus adalah pendekatan kualitatif yang penelitinnya mengeksplorasi kehidupan nyata, sistemterbataskontemporer (kasus) atauberagamsistemterbatas (berbagaikasus), melalui pengumpulan data yang detail dan mendalam yang melibatkan beragam sumber informasi atau sumber informasi majemuk dan melaporkan deskripsi kasus dan tema kasus. Satu ananalisis dalam studi kasus berupa kasus majemuk (studi multi situs), kasus tunggal (studi dalam situs) dan kasus intrinsik. Peneliti menentukan bahwa metode penelitian studi kasus ini lebih focus kejenis studi kasus instrumental tunggal. Objek penelitian adalah 
merujuk pada masalah atau tema dengan memfokuskan komunikasi terapeutik tenaga kesehatan dalam penanganan kesembuhan pasien ODGJ pasca pasung yang berada di desa Wonorejo. Sedangkan, subjek penelitian adalah responden atau informan. Peneliti dalam pengambilan subjek penelitian menggunakan purposive sampling. Kriteria yang dijadikan subyek penelitian adalah sebagai berikut: satu dokter spesialis jiwa (psikiater) yang bekerja di RSJ RW Lawang bagian instalansi PKRS, dan perawatjiwa yang ada di Posyandu Jiwa desa Wonorejo dan perawat jiwa RSJ Lawang.

Teknik pengumpulan data terhadap penelitian ini adalah observasi partisipan, wawancara mendalam, dokumentasi, dan menggunakan bahan audio visual. Teknik analisis peneliti mendiskripsikan tentang 1)kasus dengan pemain utama, tempat, dan segala aktivitasnya; 2)kemudian dikelompokkan menjadi kategori (agregasi kategorial); 3)menyederhanakan menjadi tema; 4)mengembangkan generalisasi tentang kasus dalam sudut pandang tema yaitu menyampaikan kebermanfaannya untuk diri sendiri dan masyarakat atau orang lain; 5)kemudian dibandingkan/ dikontraskan dengan literatur terbitan tentang hal yang dibahas. Sedangkan Teknik keabsahan, menggunakan triangulasi dan member cek.

\section{HASIL}

Tenaga kesehatan yang dimaksud dalam pembahasan ini adalah psikiater (dokter kesehatan jiwa), dan perawat yang ada di Posyandu Jiwa dan Rumah Sakit Jiwa Lawang. Mereka bekerja sama dalam melaksanakan tugas untuk mengobati pasien-pasien ODGJ pascapasung yang ada di Desa Wonorejo. Pengobatan berupa terapi ini adalah kelanjutan dari terapi Rumah Sakit Jiwa Lawang. Karena sebelumnya, mereka mendapatkan perawatan di Rumah Sakit Jiwa Lawang selama 43 hari dengan memakai BPJS. Setelah kondisinya sudah stabil dan tenang, mereka dipulangkan ke rumah masing-masing kembali ke desa Wonorejo.

Pasien ODGJ pasca pasung akan mendapatkan perawatan di Posyandu Jiwa desa Wonorejo, dalam satu bulan satu kali pertemuan pada minggu ke-3 hari Senin secara rutinitas. Hal ini dilakukan agar pasien teratur dalam mengikuti terapi lanjutan dari Posyandu Jiwa dengan dibina oleh PKRS (Promosi Kesehatan Rumah Sakit) Dr Radjiman Wediodiningrat Lawang. Apa yang dilakukan oleh tenaga kesehatan terhadap pasien ikut serta dibantu oleh kaderkader jiwa yang ada di desa Wonorejo secara suka rela. Melihat hasil observasi dan wawancara Penulis sejak mulai bulan April sampai dengan November 2018, penulis mengkategorikan bahwa komunikasi terapeutik yang dilakukan oleh tenaga kesehatan adalah terapi medis (medical therapy) dan terapi non medis (nonmedical therapy).

\section{Komunikasi Terapeutik Psikiater}

\section{(1) Telepsychiatry}

Telepsychiatry ini dilakukan antara psikiater dan pasien ODGJ pasca pasung yang didampingi oleh perawat di Posyandu Jiwa desa Wonorejo Kecamatan Singosari Kabupaten Malang. Pada pelaksanaannya psikiater bersama operator Rumah Sakit Jiwa Lawang yang berada di Rumah Sakit Jiwa Lawang memanfaatkan teknologi komunikasi menggunakan media skype (Video call) yang ada di komputer kemudian dihubungkan dengan jaringan internet agar bisa menjangkau jarak jauh ke Posyandu Jiwa. Di Posyandu Jiwa juga perawat dan pasien sudah mempersiapkan media skype yang dihubungkan dengan jaringan internet, dengan dilengkapi headset bisa juga pengeras suara komputer untuk membantu pendengaran dari pembicaraan antara psikiater, pasien, dan perawat.

Tujuan Telepsychiatry ini adalah mengetahui kondisi perkembangan pasien secara psikis maupun fisik, dengan cara pasien berkonsultasi dengan psikiater yang didampingi perawat. Pasien mengungkapkan keluhan-keluhan yang dirasakan setelah pengobatan satu bulan sebelumnya dari Rumah Sakit Jiwa Lawang maupun rutinitas pengobatan di Posyandu Jiwa desa Wonorejo ini. Keuntungan dari telepsychiatry ini adalah mendekatkan jarak jauh dalam pengobatan melalui media dengan cara berkonsultasi untuk observasi kondisi pasien terkini, meringankan beban pasien secara materi karena rata-rata pasien di desa Wonorejo kondisi ekonomi kurang mampu. 


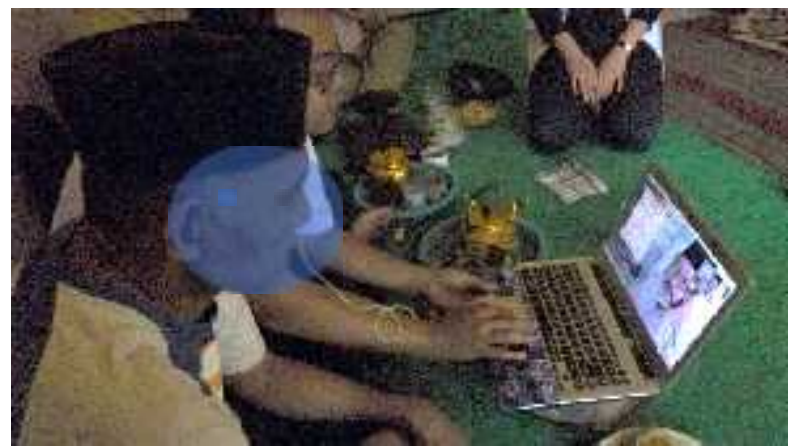

Gambar 1: Proses Telepsychiatry

Pada gambar di atas proses telepsychiatry berlangsung antara psikiater dr Eko, pasien ODGJ yang didampingi oleh perawat. Substansi isi komunikasi terapeutik pada saat proses telepsychiatry berlangsung perawat "B" salah satu perawat Rumah Sakit Jiwa Lawang menyampaikan bahwa:

"Mengenai perkembangan sikap, afektif, psikomotor, dan kognitif,...evaluasi tanda gejala gangguannya, apakah masih ada suara, apa masih ada bayangan, apa masih ada emosi marah atau sedih berlebih, dan sebagainya, kemudian istirahat tidur dan perawatan dirinya, karena salah satu indikator kemandirian ADL kan itu adapula kepatuhan terhadap pengobatannya bagaimana, untuk keberlangsungan terap dan yang terakhir bagaimana fungsi sosialnya, interaksinya dengan tetangga, keinginan untuk beraktivitas bersama kelompok lain, dan sebagainya...(Hasil Wawancara dengan Perawat Rumah Sakit Jiwa Lawang, tanggal 15 November 2018).

Sebagaimana yang disampaikan perawat Benny, bahwa psikiater dalam melaksanakan komunikasi terapeutik pada pasien ODGJ post pasung di desa Wonorejo menanyakan kepada perawat dan pasien tentang sikap baik afektif, kognitif maupun psikomotornya. Bagaimana emosi pasien dalam kesehariannya pakah sudah stabil atau belum, bagaimana tentang kegiatan kesehraiannya, bagaimana pasien bersosialisasi dengan lingkungan rumah maupun sekitarnya, dan yang paling penting adalah bagaimana kepatuhan terhadap konsumsi obatnya, apakah dosisnya bisa diturunkan atau dinaikkan, atau bahkan diganti obatnya tergantung kondisi pasien.

Psikiater mengetahui kondisi psikis bisa dilihat dari monitor komputer, ketika telepsychiatry berlangsung dari mimik wajahnya, gerakangerakan yang dilakukan oleh pasien. Apakah pasien sudah stabil atau belum bisa dilihat dari kondisi psikisnya melewati monitor. Kemudian psikiater memberikan saran kepada perawat yang mendampingi pasien mengenai pemberian obat, dan saran kepada pasien untuk selalu disiplin dalam menjalani terapi bulanan yang diadakan Posyandu Jiwa ini.

\section{(2) Terapi Obat}

Terapi pemberian obat ini adalah pemberian obat kepada pasien ODGJ pasca pasung secara teratur setelah menerima resep dari psikiater. Pemberian obat ini dilakukan setiap bulan oleh Posyandu Jiwa desa Wonorejo setelah pemeriksaan kesehatan pasien ODGJ. Dari hasil pemeriksaan itu mengetahui bagaimana perkembangan pasien satu bulan sebelumnya adanya Posyandu Jiwa, ketika pasien tertib meminum obat seperti apa yang disarankan oleh psikaiter maupun perawat, pasien akan mengalami perkembangan pesat, ketika pasien tidak patuh pada konsumsi obat ketika di rumah, maka pasien akan mengalami penurunan kesehatan jiwanya.

Peranan keluarga di rumah penting bagi pasien selain mengajari pasien untuk bersosialisasi, mereka selalu mengingatkan pasien untuk patuh kepada obat seperti apa yang disampaikan oleh perawat Benny. Jadi terapi obat ini sangat membutuhkan pengawasan dari pihak keluarga. Keluarga harus bekerjasama dengan psikiater dan perawat dalam menerapi obat kepada pasien ODGJ pascapasung ketika di rumah. Peranan keluarga pasien itu sangat penting sekali, untuk memulihkan kondisi pasien agar pasien tidak mengalami kekambuhan dan re-pasung. 


\section{Komunikasi Terapeutik Perawat}

Handycraft

Handycraft ini adalah termasuk bagian kegiatan rehabilitasi mental. ODGJ pasca pasung bersama perawat dan kader jiwa bekerjasama dalam mengerjakan keterampilan tangan. Keterampilan tangan ini berupa pembuatan kemoceng, pembuatan keset, pembuatan sandal, pembuatan bros, pasien dipandu oleh kader jiwa maupun perawat.

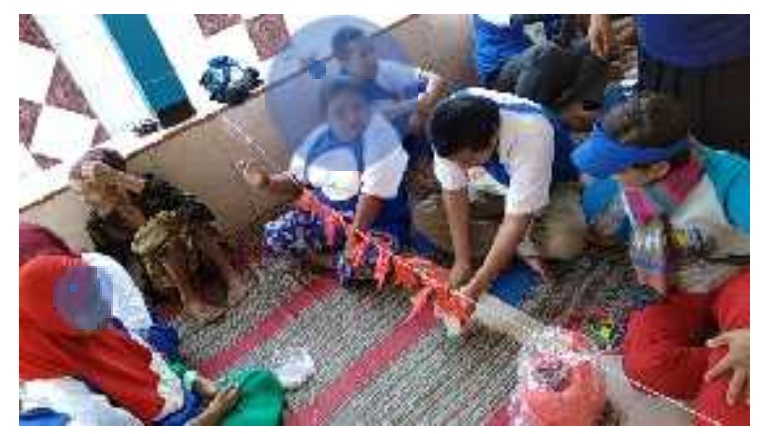

Gambar 2. Pembuatankemoceng ODGJ pascapasung

Pada gambar 2, sebagian dari kegiatan handycraft dari pasien-pasien ODGJ yang ada didesa Wonorejo dalam pelayanan rehabilitasi mental. Tujuannya dalam rehabilitasi mental pada handycraft ini adalah memberikan keterampilan kepada pasien ODGJ pasca pasung untuk mengembalikan produktifitas mereka agar tetap survival dalam mempersiapkan kehidupan ketika mereka kembali ke masyarakat. Karena selama mereka menjadi ODGJ dari sistem afeksi, kognitif, dan psikomotornya kurang berfungsi secara maksimal sehingga tidak mempunyai energi produktivitas dalam berkarya. Padahal dalam kondisi normal sebelumnya pasien adalah orang-orang yang bekerja keras seperti bertani, mayoritas penduduk desa Wonorejo adalah bertani kayu sengon dan palawijo adapaun tukang batu.

\section{Terapi Psikoreligius}

Terapi psikoreligius ini diberikan kepada pasien ODGJ pascapasung ini dengan cara berdzikir, bersholawatan, dan himbaun untuk melaksanakan sholat maupun mengaji ketika di rumah dengan melibatkan peran serta keluarga dirumah. Pasien ODGJ pasca pasung ini mayoritas beragama Islam, maka terapinya dengan seperti itu, sehingga keseimbangan pengobatan yang dilakukan psikiater maupun perawat yang dibantu kader jiwa terpenuhi.

Pada pelaksanaan terapi psikoreligius ini pasien ODGJ pasca pasung yang ada di Posyandu Jiwa desa Wonorejo dipandu oleh perawat yang memahami bagaimana terapi psikoreligius dan yang jelas beragama Islam. Karena Terapi psikoreligius ini ketika di
Rumah Sakit Jiwa berbagai agama pasien yang masuk untuk melakukan perawatan inap, pihak Rumah Sakit Jiwa menyediakan terapis-terapis yang beragama Kristen, Hindu, bahkan Budha jika ada.

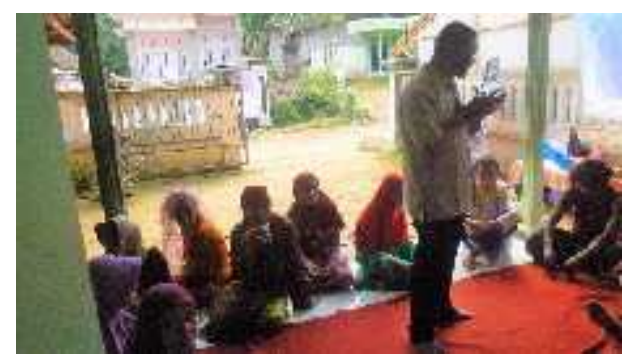

Gambar 3. TerapiPsikoreligius Sumber: Dokumentasipenulis

Pada gambar 3, adalah pelaksanaan terapi psikoreligius yang diadakan oleh Posyandu Jiwa desa Wonorejo, terapi ini dipimpin oleh Pak Nur sebagai pengendali jalannya terapi berlangsung, dengan meminta bantuan salah satu tokoh masyarakat untuk membimbing sholawatan maupun berdzikir bersama dengan pasien ODGJ semua. Mereka bersama-sama menirukan apa yang disampaikan oleh pemandu terapi.

\section{Terapi Aktivitas Kelompok}

Terapi Aktivitas Kelompok (TAK), selalu diadakan oleh Posyandu Jiwa desa Wonorejo sebagai terapi pelengkap untuk pemulihan kesehatan jiwa ODGJ pasca pasung. Terapi ini di pandu oleh perawat Posyandu Jiwa, dan kader-kader jiwa untuk membantunya. Terapi ini lebih kepada permainan kelompok tujuannya adalah untuk bersosialisasi antar ODGJ yang ada di desa Wonorejo. 


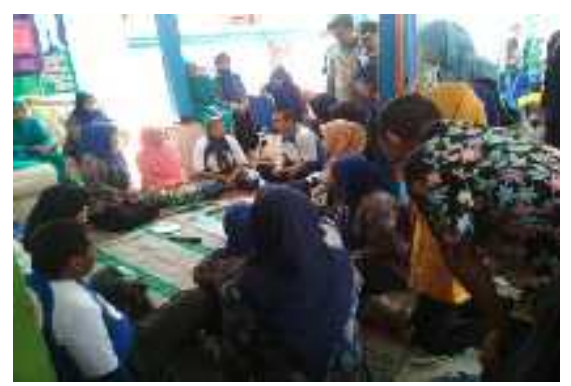

Gambar 4. TerapiAktivitasKelompok di Posyandujiwa

Salah satu perawat menceritakan bahwa

"TAK ini isinya kegiatan permainan, saling memperkenalkan diri atau mengingat namanama teman sebelahnya, permainan musik jika musiknya berhenti pasien kena hukuman joget, memperkenalkan diri kemudian menyebutkan nama orang tuanya, dan teman-teman ODGJ yang ada di situ" (Hasil Wawancara perawat "T", 26 Oktober 2018).

\section{PEMBAHASAN}

Posyandu Jiwa ini efektif sekali dalam melakukan metode telepsychiatry yaitu dengan menggunakan model video conference dari pada menggunakan model yang lainnya yang sifatnya tidak pandang dengar. Seperti apa yang disampaikan oleh The National Library of Medicine adalah sebagai berikut:

\section{The National Library of Medicine defines,}

"telemedicine as it applies to psychiatry [telepsychiatry] as the use of electronic communication and information technologies to provide or support clinical psychiatric care at a distance. This definition includes many communication modalities such as phone, Fax, e-mail, the Internet, still imaging, and live interactive two-way audio-video communication (American Psychiatric Association resource document on telepsychiatry via videoconferencing, 1998). Live interactive two-way audio-video communication - videoconferencing-is the modality most applicable to psychiatry and has becomesynonymous with telepsychiatry involving patient care, distance education, and administration. (Antonacci, dkk, 2008: 253)".

Sebagaimana yang disampaikan The Nastional Library of Medicine, interaksi yang berlangsung secara komunikasi yang sifatnya audio visual bisa didengar dan dilihat yaitu seperti vedio conference, efektif dalam kegiatan psikiatri, dan menjadi pedukung dalam kepedulian pasien, bisa mengedukasi secara dekat, dan mempermudah adminitrasi seperti pemberian resep dokter dan adminitrasi lainnya yang berkenaan tentang kesehatan jiwa pasien. Hal itu paling efektif ketika memanfaatkan teknologi komunikasi dalam kehiatan psikiatri daripada dengan menggunakan telepon, email, maupun fax.

\section{Terapi Obat}

Berbicara mengenai terapi obat kepada pasien ODGJ pasca pasung, dalam pharmaceutical care tidak hanya berorientasi pada pemberian obat, akan tetapi juga pada pengambilan keputusan tentang jenis obat yang akan diberikan kepada penderita, juga dalam mengambil keputusan untuk tidak memberikan obat yang tidak sesuai dengan tujuan terapi, dosis, cara lain dan metode pemberian obat kepada penderita (Surahman dan Husen, 2011:10). Dalam pemberian obat ini, harus mengetahui resep yang diberikan oleh psikiater termasuk dosisnya dan waktu pemberian obat kepada pasien, karena yang mengetahui kondisi setelah pemeriksaan pasien adalah psikiater, bersama perawat.

\section{Komunikasi Terapeutik Perawat Handycraft}

Pelayanan rehabilitasi yang berupa handycraft di Posyandu Jiwa desa Wonorejo ini dirancang untuk meningkatkan proses perbaikan pasien yang mengalami gangguan mental dalam mengontrol gejala dan penatalaksanaan pengobatan meliputi peningkatan kemampuan diri kembali ke masyarakat, pemberdayaan, meningkatkan kemandirian dan kualitas hidupnya.

Tujuan dari rehabilitasi adalah untuk menghadapi stigma buruk yang ditujukan pada pasien ODGJ pasca pasung setelah pulang ke rumah. Menurut Mallone dalam (Mental Health Rehabilitation Concept, 1989) dikutip 
oleh Yosep dan Sutini (2014:325-326) adalah sebagai berikut: survival skills (kemampuan berjuang hidup), cooperation (kemampuan bekerjasama), hanging out (mengembangkan hubungan pertemanan), backing (kemampuan membantu orang lain), supplementing(menyediakan material seperti makanan dan minuman), checking up (memeriksakan diri).

\section{Terapi Psikoreligius}

Pencapaian terapi ini bagi pasien ODGJ desa Wonorejo adalah sebagai pengobatan secara rohaniahnya agar tetap terjaga kestabilan dan keseimbangan kesehatan jiwanya, agar tidak mudah untuk menuruti halusinasi pendengaran terutama yang negatif seperti menyuruh bunuh diri dengan masuk sumur, menabrakkan diri, dan delusi atau keyakinan yang sama sekali tidak ada.

Terapi keagamaan (intervensi religi) pada kasus-kasus gangguan jiwa ternyata juga membawa manfaat. Misalnya angka rawat inap pada klien skizofrenia yang mengikuti kegiatan keagamaan lebih rendah bila dibandingkan dengan mereka yang tidak mengikutinya (Chu dan Klien, 1985) dikutip oleh Yosep dan Sutini (2014:368). Studi Stark menunjukkan bahwa angka frekuensi kunjungan ke temapt ibadah lebih merupakan indikator dan faktor yang efektif dalam hubungannya dengan penurunan angka bunuh diri. Sedangkan klien yang tidak diberikan terapi psikoreligius pada suicide memiliki resiko 4 kali lebih besar untuk melakukan bunuh diri (Camstok dan Partiridge, 1972) dikutip oleh Yosep dan Sutini (2014:368).

Banyaknya kejadian bunuh diri dari pasien ODGJ karena kurangnya atau tidak adanya terapi religi baik di Rumah Sakit, panti, di rumah sendiri. Peranan dalam terapi religi penting sekali selain pengobatan secara medis. Berdzikir dan sholawatan yang dilakukan Posyandu Jiwa desa Wonorejo sangat membantu kondisi kejiwaan pasien. Dengan berdzikir, hati seseorang akan terasa tenteram. Ini adalah mutlak. Dalam Al Qur'an dan sabda Rasulullah SAW bahwa dzikir kepada Allah adalah obat penyakit hati, dengan syarat ia harus beriman dan ikhlas. Karena dzikir yang ikhlas akan mendatangkan rasa senang, optimis, dan persepsi positif. Ketika hal itu dikerjakan secara terus menerus tidak hanya di Posyandu Jiwa saja tetapi dikerjakan di rumah semakin frekuensinya tinggi semakin baik kondisi kejiwaan seseorang atau pasien ODGJ post pasung yang ada di desa Wonorejo.

\section{Terapi Aktivitas Kelompok}

TAK lebih melatih keterampilan kognitif, afektif, dan psikomotorik, karena pasien diajak untuk berpikir mengingat nama, orang tua, teman, dan permainan lainnya. Merasakan keberadaan orang-orang disekitarnya. Permainan yang menggunakan gerak seperti menari itu adalah hal yang membuat diri pasien merasa bahagia artinya gangguan jiwanya bisa menurun karena ada stimulusstimulus eksternal yang ada disekitarnya.

Terapi Aktifitas Kelompok ini sering dipakai menjadi terapi tambahan. Sejalan dengan hal tersebut, maka Lancaster mengemukakan beberapa aktifitas yang digunakan pada TAK, yaitu menggambar, membaca puisi, mendengarkan musik, mempersiapkan meja makan, dan kegiatan sehari-hari yang lain. Wilson dan Kneils (1992) dikutip oleh Dalami, 2010:125, menyatakan bahwa TAK adalah manual, rekreasi, dan teknik kreatif untuk memfasilitasi pengalaman seseorang serta meningkatkan respons sosial dan harga diri.

\section{Relevansi Teori Interaksi Simbolik}

Relevansi teori Interaksi Simbolik dengan tema ini adalah sangat berhubungan dalam proses komunikasi terapeutik baik secara medis maupun non medis antara psikiater, perawat dan pasien melibatkan interaksi satu sama lain dengan berbagai simbol verbal maupun nonverbal.

\section{Pikiran}

Mead mendefinisikan pikiran (mind) sebagai kemampuan untuk menggunakan simbol yang mempunyai makna sosial yang sama, dan Mead percaya manusia harus mengembangkan pikiran melalui interaksi dengan orang lain. Menggunakan bahasa dan berinteraksi dengan orang lain, kita mengembangkan apa yang dikatakan Mead sebagai pikiran, dan ini membuat kita mampu menciptakan setting interior bagi masyarakat yang kita lihat beroperasi di luar diri kita. Jadi pikiran dapat digambarkan sebagai cara orang menginternalisasi masyarakat. Akan tetapi pikiran tidak hanya tergantung pada 
masyarakat. Mead menyatakan keduanya mempunyai hubungan timbal balik. Pikiran merefleksikan dan menciptakan dunia sosial. Ketika seseorang belajar bahasa, ia belajar berbagai norma sosial dan aturan budaya yang mengikatnya. Selain itu ia juga mempelajari cara-cara untuk membentuk dan mengubah dunia sosial itu melalui interaksi.

Proses komunikasi terapeutik ini melibatkan psikiater, perawat dan pasien. Dalam berinteraksi antara psikiater, perawat dan pasien, mereka melibatkan bahasa sebagai media komunikasi untuk berinteraksi dalam proses komunikasi terapeutik. Pada proses interaksi berlangsung psikiater harus memahami makna dari simbol yang diberikan pasien maupun perawat yang mendampingi pasien. Diantara mereka terjadi persamaan pemaknaan dalam merespon pesan. Bagaimana ketika pasien diterapi oleh psikiater melalui telepsychiatry dengan melihat kondisi secara verbal, bagaimana pasien berkomunikasi dan bagaimana perawat berbicara dengan psikiater. Secara nonverbal, bagaimana psikiater harus mengetahui kondisi pasien dengan melihat gerakan mimik wajahnya, raut mukanya apakah dia sehat atau sebaliknya. Psikiater memahami bahasa-bahasa nonverbal yang dikirimkan pasien melalui tayangan pada metode telepsychiatry. Pada interaksi dengan melakukan observasi melalui telepsychiatry antara psikiater, perawat, dan pasien, selanjutnya psikiater memberikan resep obat atau dengan terapi obat kepada pasien agar pasien mengalami peningkatan kesehatan jiwanya.

Terkait dengan konsep pikiran adalah pemikiran (thought), yang dinyatakan oleh Mead sebagai percakapan di dalam diri sendiri. Mead berpegang bahwa tanpa rangsangan sosial dan interaksi dengan orang lain orang tidak akan mampu mengadakan pembicaraan dalam dirinya sendiri atau mempertahankan pemikirannya. Salah satu aktivitas penting menurut Mead, yang diselesaikan orang melalui pemikirannya adalah pengambilan peran (role taking), atau kemampuan secara simbolik menempatkan dirinya sendiri dalam diri khayalan dari orang lain. Proses ini juga disebut pengambilan perspektif karena kondisi ini mensyaratkan bahwa seorang menghentikan perspektifnya sendiri terhadap sebuah pengalaman dan sebaliknya membayangkannya dari perspektif orang lain. Mead menyatakan bahwa pengambilan peran adalah sebuah tindakan simbolis yang dapat membantu menjelaskan perasaan kita mengenai diri dan juga memungkinkan kita untuk mengembangkan kapasitas untuk berempati dengan orang lain.

Psikiater dan perawat terhadap pasien ODGJ pasca pasung yang ada di desa Wonorejo selalu berempati kepada pasien. Bahwa dalam pandangan mereka pasien ODGJ itu adalah orang yang harus diobati penyakitnya melalui beberapa terapi, salah satunya adalah komunikasi terapeutik yaitu komunikasi yang sangat efektif dalam meningkatkan kesehatan jiwa pasien ODGJ desa Wonorejo, ketika pasien didengarkan, disentuh, diajak bermain, berkarya, dalam satu ruang itu adalah hal yang membahagiakan bagi pasien ODGJ post pasung. Sebagai tenaga kesehatan harus masuk di dalamnya, dengan berempati menempatkan diri kita dalam posisi mereka.

\section{Diri}

Mead mendefinisikan diri (self) sebagai kemampuan untuk merefleksikan diri kita sendiri dari perspektif orang lain. Bagi Mead, diri berkembang dari sebuah jenis pengambilan peran yang khusus maksudnya, membayangkan bagaimana kita dilihat oleh orang lain. Meminjam konsep yang berasal dari seorang sosiologis Charles Cooley pada tahun 1912, Mead menyebut hal tersebut sebagai cermin diri (looking glass self), atau kemampuan kita untuk melihat diri kita sendiri dengan pantulan dari pandangan orang lain. Cooley (1972), menyakini tiga prinsip pengembangan yang dihubungkan dengan cermin diri: (1) kita membayangkan bagaimana kita terlihat dimata orang lain, (2). Kita membayangkan penilaian mereka mengenai penampilan kita, (3). Kita merasa tersakiti atau bangga berdasarkan perasaan pribadi ini. Kita belajar mengenai diri kita sendiri dari cara orang lain memperlakukan kita, memandang kita, dan memberi label kepada kita.

Komunikasi terapeutik dalam riset ini berhubungan dengan komunikasi psikiater, perawat, dan pasien. Dalam perspektif diri mereka mempunyai kemampuan merefleksikan 
diri dari persepektif orang lain. Psikiater dan perawat jiwa pandangan orang lain terhadap profesi ini adalah jiwa penolong bagi pasien gangguan jiwa. Mempunyai tugas untuk mengurangi orang-orang yang terganggu jiwanya menjadi pribadi yang sehatnya jiwanya untuk beraktivitas kembali ke masyarakat. Berbeda lagi ketika orang lain menilai ODGJ bahwa mereka adalah adalah orang gila, orang yang tidak mempunyai akal, sakit jiwanya, kotor, sampah, gelandangan. Sangat kasihan ketika diri ODGJ dipandang masyarakat sebelah mata. Seolah-olah bahwa mereka adalah orang yang tidak berguna hanya seperti kotoran yang menghiasi setiap sudut jalan.

\section{Masyarakat}

Mead berargumen bahwa interaksi mengambil tempat di dalam sebuah struktur sosial yang dinamis - budaya, masyarakat, dan sebagainya. Individu-individu lahir ke dalam konteks sosial yang sudah ada. Mead mendefinisikan masyarakat (society) sebagai jejaring hubungan sosial yang diciptakan manusia. Individu-individu terlibat di dalam masyarakat melalui perilaku yang mereka pilih secara aktif dan sukarela. Jadi, masyarakat menggambarkan keterhubungan beberapa perangkat perilaku yang terus disesuaikan oleh individu-individu. Masyarakat ada sebelum individu tetapi juga diciptakan dan dibentuk oleh individu, dengan melakukan tindakan sejalan dengan orang lainnya. (Forte, 2004) dalam (West dan Turner, 2014:107).

Pemikiran Mead mengenai orang lain secara khusus (particular others) merujuk pada individu-individu dalam masyarakat yang signifikan bagi kita. Orang-orang ini biasanya adalah anggota keluarga, teman, kolega di tempat kerja serta supervisor. Kita melihat orang lain secara khusus tersebut untuk mendapatkan rasa penerimaan sosial dan rasa mengenai diri. Pada particular other, keluarga paling dekat adalah orang-orang yang mau menerima kondisi keluarganya menjadi ODGJ begitupula dengan psikiater, perawat maupun kader jiwa. Realitasnya melihat fenomena yang ada di desa Wonorejo bahwa ODGJ pasca pasung maupun non pasung, mereka sangat diperhatikan oleh keluarganya apalagi adanya perawatan kesehatan jiwa melalui Posyandu Jiwa yang ada di desa Wonorejo.
Bahkan mereka sangat peduli, ketika perawat mengadakan edukasi atau berkunjung kerumah pasien untuk memberikan edukasi kesehatan berkaitan dengan kepatuhan minum obat, menanyakan perkembangan kesehatan jiwa pasien, memberikan support tentang ADL aktivitas daily pasien.

Psikiater, perawat, dan kader jiwa yang terlibat dalam perawatan lanjutan di Posyandu Jiwa adalah termasuk particular other, sangat menerima pasien ODGJ pasca pasung. Agar tujuan mereka bisa tercapai yaitu memberikan terapi secara intensif dan mencapai kesembuhan maksimal. Orang lain secara umum (generalized other) merujuk pada cara pandang dari sebuah kelompok sosial atau budaya sebagai suatu keseluruhan. Hal ini diberikan oleh masyarakat kepada kita, dan sikap dari orang lain secara umum adalah sikap dari keseluruhan komunitas" (Mead, 1934: 154) dalam West dan Turner (2014: 107-108).

Mengenai generalized other, yang dihubungkan dengan ODGJ post pasung di desa Wonorejo adalah suatu hal yang lumrah, hal sudah biasa. Masyarakat desa Wonorejo memandang bahwa ODGJ menurut mereka adalah perlu dirangkul tidak perlu untuk didiskiminasikan karena mereka juga mempunyai hak untuk dikasihani, untuk hidup selayaknya seperti kita. Tetapi berbeda lagi masyarakat luar yang masih awam mereka justru menyebut ODGJ adalah orang gila atau orang yang tidak waras. Hal ini tenaga kesehatan memang perlu menjadi penengah atas konflik yang ada di masyarakat bagaimana mereka memandang keberadaan ODGJ secara realitas. Ketika ODGJ sudah mendapatkan perawatan dari Rumah Sakit Jiwa dan perawatan berkelanjutan seperti yang ada di Posyandu Jiwa desa Wonorejo ini, ODGJ bisa untuk diajak berkomunikasi, dan bisa beraktivitas kembali seperti sedia kala.

\section{SIMPULAN DAN SARAN}

\section{Simpulan}

Komunikasi terapeutik tenaga kesehatan terhadap Orang dengan Gangguan Jiwa (ODGJ) di Posyandu Jiwa desa Wonorejo, merupakan komunikasi yang dilakukan psikiater dan perawat bersama kader jiwa untuk melakukan perawatan berkelanjutan dengan melalui komunikasi terapeutik 
psikiater dan komunikasi terapeutik perawat, yang dilaksanakn di Posyandu Jiwa setiap bulan dalam minggu ke tiga tepatnya hari Senin.

Komunikasi terapeutik psikiater ini adalah dari tenaga kesehatan kepada pasien ODGJ pasca pasung adalah dengan melakukan Telepsychiatry jarak jauh dan terapi obat, yang melibatkan psikiater dibantu perawatyang mendampingi pasien untuk mengadakan konsultasi melalui video conference dengan memanfaatkan media Skype di komputerdengan terhubung jaringan internet. Ini dilakukan pada psikiater yang berada di Rumah Sakit Jiwa Kecamatan Lawang dengan pasien bersama perawat yang ada di Posyandu Jiwa desa Wonorejo Kecamatan di Singosari. Substansi dari telepsychiatry adalah berisi komunikasi observasi kondisi kesehatan jiwa pasien ODGJ pasca pasung. Setelah selesai tele kemudian pasien akan diberikan resep obat melalui perawat untuk diberikan obat sesuai dengan dosis yang diberikan oleh perawat.

Terapi komunikasi perawat, ini berkaitan dengan terapi tambahan yaitu pembuatan keterampilan tangan seperti pembuatan kemoceng, pembuatan sandal, pembuatan bros, dan pembuatan keset itu adalah bagian dari rehabilitasi mental dalam pemberdayaan ODGJ yang siap untuk kembali ke masyarakat lagi. Karena dengan keterampilan itu mereka bisa survival atas hidupnya secara mandiri. Terapi psikoreligius adalah terapi yang mengedepankan terapi yang isinya dengan keagamaan yaitu berdzikir, sholat, bersholawat, berdoa, mengaji, lebih kepada hubungan ke vertikal yaitu Allah SWT. Hal ini akan mengurangi resiko bunuh diri karena halusinasi negatif dan delusi yang berlebihan. Terapi Aktivitas Kelompok adalah terapi yang dilakukan untuk semua anggota ODGJ yang ada di Posyandu Jiwa Wonorejo untuk bermain, dan bersosialisasi, guna memperbaiki fungsi kognitif, afektif, dan psikomotorik pada diri ODGJ pasca pasung.

Relevansi dengan teori Interaksi Simbolik dilihat dari konsep pikiran atau mind, diri, dan masyarakat. Komunikasi terapeutik adalah hasil pikiran dari hubungan diantara psikiater, perawat dan pasien karena dalam komunikasi mereka ada bahasa dengan simbol-simbol yang dipertukarkan diantara mereka dengan mempunyai pemaknaan yang sama. Ketika hal ini sejalan tujuan dari komunikasi terapeutik adalah efektif. Diri ini bisa dilihat dari diri sebagai psikiater, perawat, dan ODGJ pasca pasung didesa Wonorejo. Psikiater dan perawat dilihat sebagai penolong jiwa yang berhati ikhlas, ODGJ dilihat sebagai orang yang perlu dikasihani, disentuh, dan dirangkul, ada juga yang memandang bahwa ODGJ adalah orang gila, atau orang yang tidak waras. Pada poin masyarakat, bahwa yang menjadi particular others adalah keluarga yang selalu menyayangi mereka, begitupula dengan psikiater, perawat, dan kader jiwa, generalized others adalah masyarakat yang ada di dalam wilayah kekuasaan maupun diluar kekuasaan. Masyarakat di dalam kekuasaan memandang bahwa ODGJ desa Wonorejo adalah sudah biasa mereka tidak takut, tidak mencemooh, tidak memandang rendah, tetapi berbeda lagi masyarakat di luar wilayah kekuasaan mereka akan memandang rendah ODGJ, orang gila, tidak waras, tidak berfungsi dalam bermasyarakat secara baik.

\section{Saran}

Membangun kerjasama secara terus-menerus antara pihak yang berwenang seperti Dinas Kesehatan, Dinas Sosial, Rumah Sakit Jiwa, Puskesmas, dan Pemerintah Desa untuk selalu memperhatikan kasus-kasus kesehatan jiwa diberbagai daerah. Mendirikan posyanduposyandu jiwa diberbagai kecamatan itu kebutuhan yang sangat penting dalam meminimalisir keluarga yang memasung anggota keluarganya yang gangguan jiwa, dan pengobatan bisa terkontrol pada setiap bulannya.

Akademisi memperbanyak kajian-kajian dengan berbagai pendekatan sesuai dengan disiplin ilmu yang pro terhadap kesehatan jiwa, agar kasus-kasus kesehatan jiwa bisa terangkat dan tertangani dengan baik. Dapat meminimalisir kasus pasung, kasus gangguan jiwa yang tidak tertangani pada keluarga yang kurang mampu, kemudian orang dengan gangguan jiwa liar dijalanan.

\section{DAFTAR PUSTAKA}

Antonacci, Diana J., Richard M. Bloch,Sy Atezaz Saeed, Yilmaz Yildirim, dan Yand Jessica Talley. 2008. Empirical Evidence on the Use and Effectiveness 
of Telepsychiatry via Video conferencing: Implications for Forensic and Correctional Psychiatry. Behavioral Sciences and the Law Behav. Sci. Law 26: 253-269.

Bogdan, Robert C. dan Biklen Kopp Sari.1982. Qualitative Research for Education: AnIntroduction to Theory and Methods. Boston London. Allyn and Bacon, Inc.

Creswell, John W. 1998. Qualitative Inquiry And Research Design Choosing Among Five Tradition. London New Delhi. Sage Publication.

Dalami, Ermawati. 2010. Konsep Dasar Keperawatan Kesehatan Jiwa. Jakarta. CV Trans Info Media.

Hendriyana, Artanti, 2013. http://www.unpad.ac.id/profil/drsuryani-skp-mhsc-setiap-tahunpenderita-gangguan-jiwa-di-indonesiaterus-meningkat/, 10/26/2017, 1:37.

Idrus, Muhammad. 2009. Metode Penelitian Sosial (PendekatanKualitatif dan Kuantitatif). EdisiKedua Yogyakarta. Erlangga.

Kreps, Gary L, Barbara C. Thornton. 1984. Health Communication Theory and Practise. United States of America, Longman Inc.
Maslim, Rusdi. 2013. Diagnosis Gangguan Jiwa Rujukan Ringkas dari PPDGJ-III dan DSM. Jakarta. Bagian Ilmu Kedokteran Jiwa FK-Unika Atmajaya.

PP Republik Indonesia No. 32 Tahun 1996 tentang Tenaga kesehatan.

Peraturan Menteri Kesehatan RI No. 54 Tahun 2017 Tentang Penanggulangan Pemasungan Pada Orang Dengan Gangguan Jiwa (ODGJ).

Surahman, Emma M., Ike R. Husen. 2011. Konsep Dasar Pleyanan Kefarmasian Berbasiskan Pharmaceutical Care. Bandung. Widya Padjadjaran.

Tim PKRS. 2016. Pedoman Pelayanan Mitra Jiwa Telepsikiatri - Meniadakan Jarak. Malang. RSJRW Lawang.

UU RI No. 36 Tahun 2014 Tentang Tenaga Kesehatan

West, Richard dan Lynn H. Turner. 2014. Introducing Communication Theory Analysiss and Application Third Edition. America New York.McGraw Hill Companies. 